\title{
Análisis de las dos líneas de transmisión del tratado de Tudmīr (94 H./713 e.C.)
}

\author{
Analysis of the two lines of transmission of the Treaty of Tudmìr \\ (94 H/713 e.C.)
}

\author{
Francisco FRANCO-SÁNCHEZ \\ Universidad de Alicante \\ ffransan@ua.es
}

Recibido: 3 de febrero de 2015

Aceptado: 7 de mayo de 2015

\section{RESUMEN}

Los dos textos principales de las líneas de transmisión del tratado de Tudmīr (94 H/713 e.C.), incluidos por al-'Udrī y al-Ḍabbī en sus respectivas obras, son editados y traducidos en base a la relectura de los manuscritos que los contienen; de ello se extraen una serie de conclusiones sobre su proceso de copia. Luego son comparados los dos textos entre sí y se enumeran una serie de diferencias textuales. Como conclusión se propone la hipótesis de que el texto de al-'Udnī es el más antiguo, resultado de la copia que al-'Udrī habría realizado del propio original del s. VIII (o de una copia de éste). Por otro lado, la transmisión de al-Ḍabbī sería más reciente, y sería consecuencia de poner por escrito un relato oral del texto.

Palabras clave: Pacto de Tudmīr (94 H./713 e.C.), Al-‘Udrī, Al-Dabbī, Historiografía árabe, Paleografía árabe.

\begin{abstract}
The two main texts of the transmission lines of the treaty of Tudmīr (94 H/713 e.C. ), included by al'Udrī and al-Dabbī in their respective works, are edited and translated on the basis of an new reading of the manuscripts that contain them, and after that, we reach some conclusions about its process of copy. There are compared the two texts, and are listed its textual differences. As conclusion, we propose that Al- 'Udrin's text is the oldest, because its author has copied them from the original document of the 8th. c. (or a copy transfer of this). The transmission of al-Dabbī is more recent and it was based in an oral transmission of the text.

Keywords: Pact of Tudmīr (94 H./713 e.C.), Al-“Udrī, Al-Ḍabbī, Arabic Historiography, Arabic Paleography.

SUMARIO: 1. Preliminar, 2. El texto del tratado de Tudmīr transmitido por al-'Udnrī en su Tarșī' alajbār, 3. El texto de la Bugya de al-Ḍabbī, 4. Conclusiones del análisis comparativo de los textos de las dos versiones básicas en el ámbito del derecho, 5. Las dos líneas de transmisión del texto del tratado, 6. Fuentes árabes citadas abreviadamente.
\end{abstract}




\section{PRELIMINAR ${ }^{1}$}

Como desarrollo de una reciente contribución de María Jesús Viguera a la comprensión del tratado de Teodomiro, ${ }^{2}$ así como de otro estudio publicado en el mismo monográfico, ${ }^{3}$ en el presente, se ofrece un más completo análisis comparativo de las dos líneas de transmisión árabes del tratado de Tudmīr: la de al-‘Udrī̄ y la de al-Ḍabbī.

El objetivo es extraer conclusiones relevantes acerca de la antigüedad y carácter esencial de los textos originales de cada una de las dos transmisiones esenciales en árabe del tratado. La metodología será la comparación de los dos textos, tanto en su morfosintaxis y terminología empleadas, como en las informaciones que contienen.

Obviaremos el resto de textos árabes que evolucionan de la versión de al-Ḍabbī, así como la más que posible, aunque perdida, versión tardolatina del tratado. ${ }^{4}$

${ }^{1}$ La investigación y la trascendencia de la obra escrita de María Jesús Viguera es incuestionable en múltiples campos sobre al-Andalus, y no sólo en lo relativo a su historia, sino también en diversos ámbitos de lo que ahora se denomina como "cultural history" (entendida como el estudio de la producción cultural en su sentido más amplio, con finalidades históricas, o historiográficas), como parte constitutiva de la historia de la cultura andalusí, con incursiones también en la literatura de al-Andalus. Sus muchas contribuciones son esenciales para el conocimiento de todos los períodos que se sucedieron en estos 900 años, incluidos el mudéjar y morisco.

En reconocimiento a esta trayectoria investigadora, se ofrece un estudio relacionado con la contribución que presentó en 2013 a las jornadas conmemorativas del XIII centenario del Pacto y la fundación de Tudmīr, trabajo excelente en el tono y en el fondo. El programa de las mismas puede consultarse [En línea] en http://www.um.es/tudmir713/programa/ [Último acceso: 2 de junio 2015], mientras que una parte de las contribuciones fueron publicadas en la revista eHumanista de la University of California-Santa Bárbara, en su serie editorial eHumanista/IVITRA, como monográfico n. 2 de la "Series Arabic and Islamic Studies", [En línea] disponible en

http://www.ehumanista.ucsb.edu/eHumanista\%20IVITRA/Volume\%205/index.shtml [Último acceso: 2 de junio 2015].

En el mismo, publica y comenta M. J. Viguera una carta, fechada en Zaragoza en 1891, de Julián Ribera a su maestro Francisco Codera. En ella Ribera, entre otras cosas, analiza la versión del texto del tratado de Teodomiro que se encuentra en el manuscrito de al-Dabbī de la Biblioteca del Monasterio de El Escorial. Aprovechando la glosa de esta carta, subraya una serie de importantes conclusiones respecto a la misma, entre las que se destaca la ausencia de puntos diacríticos del texto original del tratado del pacto - del cual éste de al-Ḍabbī sería un traslado evolucionado-, así como las reflexiones derivadas de ello a la hora de la identificación de las siete ciudades mencionadas en el texto.

${ }^{2}$ VIGUERA MOLINS, María Jesús: «Apuntes que Julián Ribera realizó sobre el Pacto de Tudmīr: Comentarios históricos e historiográficos», en eHumanista/IVITRA 5 (2014)289-311. [En línea] disponible en http://www.ehumanista.ucsb.edu/eHumanista\%20IVITRA/Volume\%205/Monografic\%20II/3_viguera .pdf [Último acceso: 2 de junio 2015].

${ }^{3}$ FRANCO-SÁNCHEZ, Francisco: «El tratado de Teodomiro en su contexto histórico y paleográfico», en eHumanista/IVITRA 5 (2014)312-348 [En línea] disponible en

http://www.ehumanista.ucsb.edu/eHumanista\%20IVITRA/Volume\%205/Monografic\%20II/4_franco.pdf [Último acceso: 2 de junio 2015].

${ }^{4}$ Ver lo apuntado en FRANCO-SÁNCHEZ, F., op. cit., § 3.3. y $§ 6$, pp. 325, 342, y stemma de la p. 343 . 


\section{EL TEXTO DEL TRATADO DE TUDMĪR TRANSMITIDO POR AL-

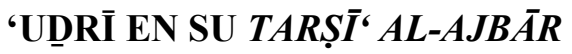

Abū 1-'Abbās Aḥmad Ibn 'Umar Ibn Anas al-'Uḍrī, Ibn ad-Dalā’̄i (393-478/10021085) en el primer capítulo de su Kitāb tarșī al-ajbār wa-tanwī' al-ātāâr wa-lbustān fì garā'ib al-buldān wa-l-masālik ilà ŷamì al-mamālik, comienza con la descripción de las diversas coras del ya extinto al-Andalus califal con la descripción de la Cora de Tudmīr. Para ello sigue el esquema expositivo oriental de al-masālik wa-l-mamälik (lo cual quiso hacer constar en el título de su obra). Curiosamente, no en la parte histórica posterior, sino en el mismo comienzo del capítulo dedicado a la Cora de Tudmīr, al hablar del nombre de la misma, recoge el texto del tratado de Tudmīr con 'Abd al-'Azīz Ibn Mūsà, cuya fijación y lectura en base a una copia del manuscrito realizamos en el estudio aludido. ${ }^{5}$

La relectura del texto árabe del manuscrito coincide con la ofrecida en su edición por 'Abd al-'Azīz al-Ahwānī, ${ }^{6}$ aunque es posible extraer algunos datos añadidos del estudio del texto del manuscrito. El texto árabe y su traducción del ms. no 243246 del Centro Ŷum'at al-Māŷid (مركز جمعة الماجد) de Dubai es el siguiente:

$$
\begin{aligned}
& \text { 1. نسخته: 7 } 7
\end{aligned}
$$

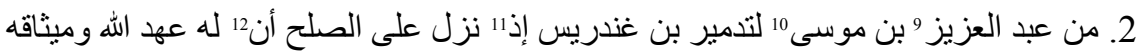

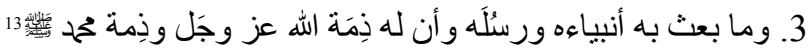

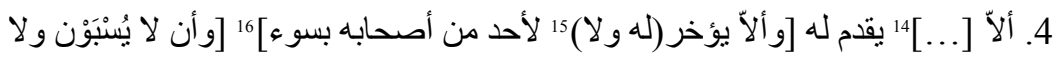

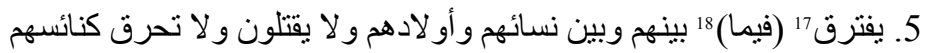

$$
\begin{aligned}
& \text { 6. و لا يكر هون على دينهم] }{ }^{19} \text { [و أن صلحهم } 20 \text { على (هذان) } 21 \text { سبع مدائن] [....... }
\end{aligned}
$$

${ }^{5}$ FRANCO-SÁNCHEZ, F., op. cit., § 4.1., pp. 325-332,

${ }^{6} \mathrm{U}-\mathrm{A}, \mathrm{pp} .4-5$.

${ }^{7}$ Indicación con que al-'Uḍñ indica que se inicia aquí la inserción de un texto diferente a su obra. Ver nota 38.

${ }^{8}$ No aparece en el texto de al-Dabbī.

${ }^{9}$ Palabra borrosa casi imposible de leer en el manuscrito original.

${ }^{10}$ Al-Ḍabbī añade la palabra: Ibn Nuṣayr

${ }^{11}$ En el texto de al-Dabbīi أنّ

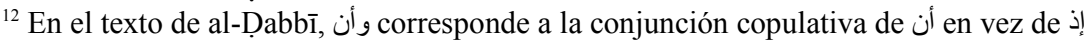

${ }^{13}$ En el texto de al-Ḍabbī وذمته وذمة نبيه

${ }^{14}$ Esta palabra está borrosa.

${ }^{15}$ Se restituye esta palabra borrosa en base a los textos de al-Himyarī y al-Ġarnātị.

${ }^{16} \mathrm{Sic}$. tal y como está recogido en el manuscrito original; en el sentido literario árabe la frase de al-

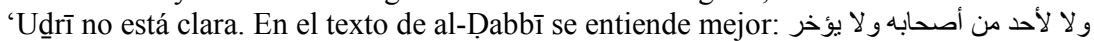

${ }^{17}$ En el ms. leemos يفترق, mientras que al-Ahwānī ha leído يفرّخر , que es más literario. No cambia el sentido. Al-Dabbī pone también يفرّق

${ }^{18}$ Palabra borrosa que restituimos hipotéticamente. 


$$
\begin{aligned}
& \text { 7. [أوزْيُولة ومُولة ولُوزْقة وبلنتلة ولَقَتَت و إيه و إلش]] } \\
& \text { 8. [و أنه لا يدع حفظ العهد ولا يحل ما انعقد ويصحح الذى فرضناه عليه و ألزمناه أمره و لا يكتمنا } \\
& \text { 9. خبراً علمه]24 وأن عليه وعلى أصحابه [غُرم الجزية من ذلك على كل حر دينار]25 وأربعة }
\end{aligned}
$$

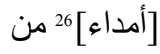

$$
\begin{aligned}
& \text { 10. قمح و أربعة [أمداء] } 27 \text { من شعير [...]28 وأربعة أقساط خل و [قسطا] } 29 \text { عسل و [قسط] }
\end{aligned}
$$

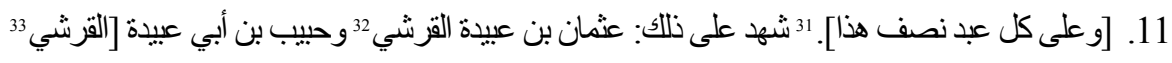

$$
\begin{aligned}
& \text { 12. وسعدان بن عبد الله الربعي وسليمان بن قيس التجيبي334 ويحيى بن يعدر السهمي وبشر] } 35 \text { بن فيس } \\
& \text { 13. (اللخمي) }
\end{aligned}
$$

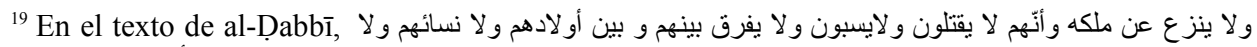

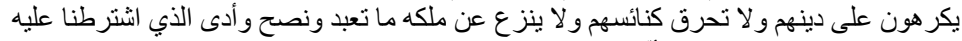

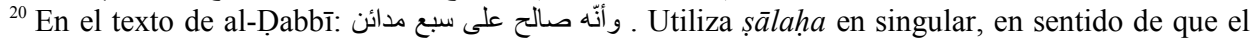
gobernante ha pactado, mientras que en al-'Uḍī la referencia es colectiva șulha-hum, refiriéndose a los que están con Teodomiro, a quienes les afecta el tratado.

${ }^{21}$ Parece que hay dos palabras, pero no se pueden leer. Restituimos hipotéticamente.

${ }^{22}$ En la página del manuscrito queda en blanco un cuarto de la línea, la parte final de la misma, que se ha dejado en blanco. En línea siguiente, se enuncian las siete ciudades repartidas equilibradamente a lo largo de toda la línea. Está claro que se ha roto el ductus de la escritura, dejándose un amplio hueco de más de una línea para introducir nuevo texto posteriormente, que en este caso son los nombres de las siete ciudades del pacto.

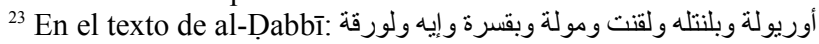

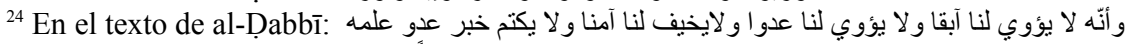

${ }^{25}$ En el texto de al-Dabbī: دينار أ كل سنة :

${ }^{26}$ En el texto de al-Dabbī. أمداد. Una nota gramatical respecto a las medidas de capacidad de sólidos: en árabe son diferentes la usada por al-'Udnin: مُدْيُ ج أمْدَاء el 'modio', es una medida más anti-

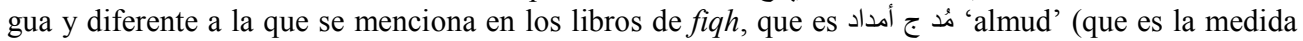
citada por al-Dabbīi). Esta segunda es la más corriente y suele utilizarse en los libros de figh cuando se trata de las limosnas a los pobres.

${ }^{27}$ En el texto de al-Ḍabbī: أمداد

وأربعة أقساط طلاء En el texto de al-'Uḍrī faltan las palabras que sí recoge al-Dabbī

${ }^{29}$ En el texto de al-Dabbī: قسطي

${ }^{30}$ En el texto de al-Ḍabbī: قسطي , esto es 2 quist de aceite, mientras que al-'Uḍ̂̄ expresa 1 quist de aceite.

وعلى العبد نصف ذلك : En exto de al-Dabbī texto

${ }^{32}$ En el texto de al-Ḍabbī عثمان بن أبي عبدة القرشيد 'Utmān Ibn Ab̄̄ 'Abda al-Qurašī

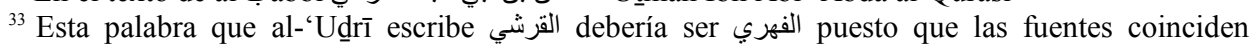
generalmente en que sea al-Fihrī. Según Ibn Taġrībirdī éste habría sido el asesino del propio 'Abd al'Azīz Ibn Mūsà, por orden directa del califa Sulaymān Ibn 'Abd al-Mālik; a él le llevó su cabeza y se la enseñó a su padre Mūsà Ibn Nuṣayr, que estaba en prisión. Este hecho le fue reprochado a Sulaymān (IT, 1: 232. En cambio ni al-Ṭabarī, ni al-Ḥumaydī o al-Ḍabbī le señalan como el asesino material (T, 4: 44; Hu-C, núm. 393, 199; D-C, núm. 675, 258-259; D-A, núm. 678, 339-340; IK, 9: 192).

${ }_{34}^{34}$ Al-Ahwānī hace una reconstrucción hipotética de esta palabra التجييب, pues es de difícil lectura.

${ }^{35}$ Estos nombres no aparecen en el texto de al-Dabbī.

${ }^{36}$ Esta palabra también se lee con dificultad en el ms de al-Ḍabbī, la hemos identificado según la lectura que hace al-Ahwānī del ms. de al-'Uḍī. 


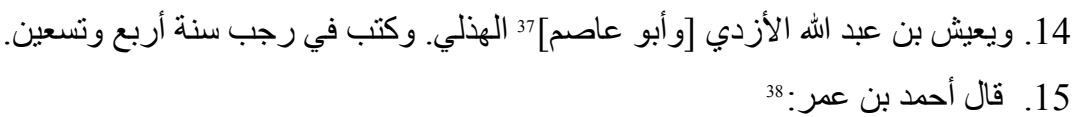

1. [Esta es] su copia:

En el nombre de Allāh, el Clemente, el Misericordioso. Este es el documento escrito [concedido]

2. por 'Abd al-'Azīz Ibn Mūsà para Tudmīr Ibn Gandarīs, en el que se ha de aplicar [lo referente] a la capitulación voluntaria: Se le concede el pacto instituido por Allāh, y su garantía,

3. según lo que ha enviado [por mediación de] sus profetas y sus mensajeros. Tiene [el estatuto de] la protección de Allāh -iensalzado y honrado

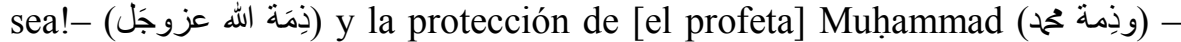
¡Allāh le bendiga y le salve!-

4. [Se le garantiza] que no [...] se le perjudicará ni a él ni a sus compañeros, sin diferencia. Que no serán hechos prisioneros, ni serán

5. separados de sus mujeres ni de sus hijos. Que no serán ejecutados. Que no serán incendiadas sus iglesias.

6. Que no serán coaccionados [a renunciar] a su religión. La sumisión voluntaria de este [tratado incluye] a siete ciudades $[\ldots \ldots]$ :

7. Orihuela (Ūryūla), Mula (Mūla), Lorca (Lūrqa), Balantala (B_1_nt_la), Alicante (Balantala), Iyih y Elche (Ilš)

8. No dejará de mantener el pacto, y no rescindirá lo pactado y no cambiará, o corregirá las condiciones que le hemos exigido. Que no nos oculte

9. ninguna información [sobre el enemigo] que tenga o llegue a su conocimiento. Que él y sus compañeros de gobierno cumplan con el impuesto de la yizya. De ella, para todo hombre libre: un dinar, cuatro modios de

10. trigo, cuatro modios de cebada, cuatro quistes de vinagre, dos quistes de miel, un quiste de aceite.

11. Y para el esclavo la mitad de todo eso. Atestiguaron esto: 'Utmān Ibn 'Ubayda al-Qurašī, Habīī Ibn Abī 'Ubayda al-Quraš̄î,

12. Sa'dān Ibn 'Abd Allāh al-Rabi'î, Sulaymān Ibn Qays al-Tuŷî̉ī, Yahyà Ibn Ya'mar al-Sahmī, Bišr Ibn Qays

13. al-Lajmī,

\footnotetext{
أبو القاسم : En el texto de al-Dabbī

${ }^{38}$ Estas palabras tiene la función de delimitar espacialmente en la página tanto el inicio del traslado textual del documento del tratado (añadiendo al inicio نسخته), como su final, añadiendo esta expresión, como indicación de que al-'Udrī vuelve a su propio relato.
} 
14. Ya'ǐš Ibn 'Abd Allāh al-Azdī y Abū 'Āșim al-Hudalīi. Se puso por escrito el mes de raŷab del año 94 [H./abril del 713 e.C.].

15. Dice Ahmad Ibn 'Umar: [vuelve a su relato].

\section{EL TEXTO DE LA BUGYA DE AL-DABBĪ}

En el diccionario biográfico de Abū Ŷa'far Aḥmad Ibn Yahyà Ibn Aḥmad Ibn 'Amīra al-Ḍabbī (m. 599/1203) titulado Bugyat al multamis fì ta' 'rìj riŷāl ahl alAndalus en tres biografías se hace mención del tratado, ${ }^{39} \mathrm{y}$ en concreto en la de Habīb Ibn Abī 'Ubayda se recoge íntegro el mismo. ${ }^{40}$ El texto árabe es el siguiente, con su traducción:

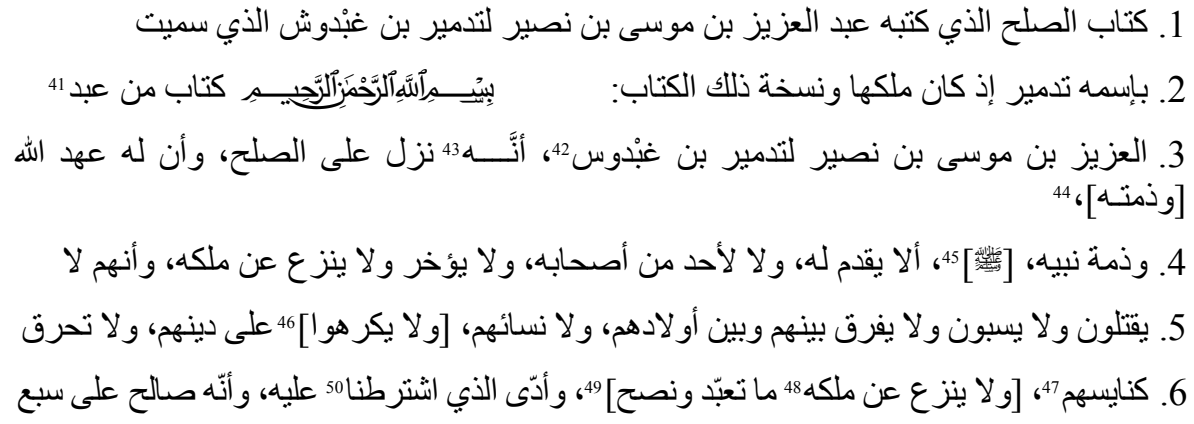

${ }^{39}$ En las biografías de 'Abd Allāh Ibn Maysara al-Fahmī y de 'Uțmān Ibn Ab̄̄ 'Abda al-Qurašī se menciona su participación en el tratado de Tudmīr, mientras que no hallamos ninguna alusión al este hecho en las biografías de otros testigos del Pacto, también recogidas en la Bugya. Ver VIGUERA, M. J., op. cit., p. 303.

${ }^{40} \mathrm{Hab} \overline{\mathrm{b}} \mathrm{b}$ Ibn Abī 'Ubayda es uno de los firmantes del pacto, con este motivo se incluye todo el texto del mismo en su biografía. El manuscrito de la Bugya de al-Dạbbī se encuentra en la biblioteca del Real Monasterio de El Escorial, ms. $\mathrm{n}^{\circ} 1676$, y el texto del pacto ocupa una página completa e independiente en el f. 84v. El texto fue editado, con una trad. lat. en D-C, pp. 105-106; ed. ár. D-CR biogr. n. 675 , pp. 258-259, espec. 259; ed. ár. D-A, biogr. n. 677, pp. 340-341.

${ }^{41}$ Se ha adoptado la escritura lógica del nombre de 'Abd عبد, pero en el manuscrito también podría leerse "Ubayd عبيد.

${ }^{42}$ En la línea 1 se escribe este mismo nombre acabado en ش y aquí, acabado en س. En las ediciones de D-A y D-C غَبْدوش.

${ }^{43}$ El copista prolonga esta palabra, que da inicio al propio texto del tratado para diferenciar visualmente el contenido.

${ }^{44}$ Es curioso cómo el copista ha alargado esta palabra para llenar con ella todo el espacio restante hasta el margen final. No se encuentra en el texto de al-Garnāțī.

${ }^{45}$ En la versión de H-LP está abreviado como (صلعم).

ولا بكر هون En la ed. ár de D-A, así como en el texto de al-Garnāṭ̄ , aparece con error ortográfico (debiendo ser 1 و لا يكر هو (d).

${ }^{47}$ En el texto de D-Ab y de Al-Himyarī كنائسهر.

${ }^{48}$ Es curiosa, por infrecuente, la repetición de la garantía de que و لا ينزع عن ملكه 'no se le relevará/enajenará de su dominio' al final de la línea 4 y al principio de la línea 6 . 


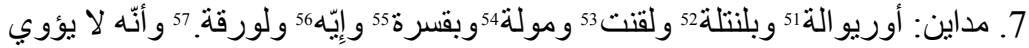

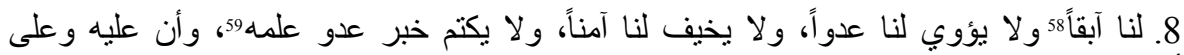

$$
\begin{aligned}
& \text { أصحابه لنا آنايه } \\
& \text { 9. دينار اً كل سنة، } 60 \text { وأربعة أمداد قمح، وأربعة أمداد شعير وأربعة أقساط طلاءء61، وأربعة } \\
& \text { 10. أقساط خل، وقسطى عسل، وقسطى زيت، و على العبد نصف ذلك. شهر على ذلك: عثمان } 62 \text { بن أبي } \\
& \text { 11. عبدة القرشي 636، وحبيب بن أبي عبيدة64 [... ...]65 (بن ميسرة الفهمي)66 و أبو قاسم67 الهذلي } \\
& \text { وكتب في } \\
& \text { 12. رجب سنة أربع وتسعين من الهجرة. }
\end{aligned}
$$

${ }^{49}$ En el texto de H-LP و لا ينزع عن كنائسه ما يعبد En el texto H-A و لا تنزع عن ملكه ما تعبّد ونصح más pare-

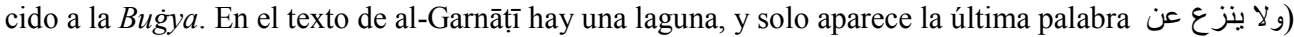

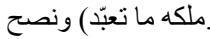

${ }^{50}$ En el texto de D-A انتنرطناه.

${ }^{51}$ En los textos de al-Himyarī y al-Garnāțîi أوريولة.

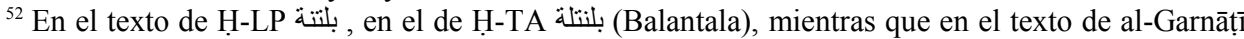
بنتيلة (Ban_tīla -o Bunatayla-).

${ }^{53}$ Ha caído del texto de al-Garnātīi.

${ }^{54}$ D-A recoge ميولة. En el texto de Ḥ-A نولة (aunque lo corrige al margen, citando a H-LP que pone مولة

${ }^{55}$ En el lugar en que la Buggya de al-Dabbī enumera بقسرة وأية (B_q_sra wa-Iy[y]a -o Iy[y]uh-) señala I. 'Abbās en su edición del Raw de de al-Ḥimyarī que aparece بلانَ) (B_lāna); en nota (Ḥ-A n. 3, p. 132) explica que en los mss. وفلانة فلانة (F_lāna wa-F_lāna, sic.) y lo aclara diciendo que el autor no habría podido leer estas dos palabras en la fuente que consultaba, por lo que escribió dos nombres indeterminados: Fulana y Fulana; de este modo, es casi seguro que este بلانة (B_lāna) proceda del indeterminado فلانة (F_lāna). En el texto de al-Garnāṭị:ة بنير (Banīa -o Bunayra-).

${ }^{56}$ En el ms. la última letra 4 sin puntos, pero D-A los pone. En H-LP escribe و ألَّله (132, nota 4, lo identifica con Ello). Ver a este respecto CARMONA, Alfonso: «La ciudad de Tudmīr», eHumanista/IVITRA 5 (2014)392-405.

${ }^{57}$ En el texto de D-C لوزقة.

${ }^{58}$ D-A la escribe إبقاء.

59 عo aparece en el texto de H-A, sí en H-LP.

${ }^{60}$ En el texto de H-A نسمة y cita en el margen que la Bug்ya y Ḥ-LP viene solo سنة .

${ }^{61}$ En el manuscrito está escrito sin hamza طل

${ }^{62}$ El copista ha escrito 'Uțmān sin alīf $f$ de prolongación, عثن.

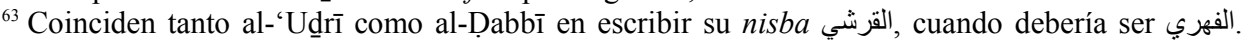
Ver lo dicho en nota 33. Esto quizás indique un origen común a las dos cadenas de transmisión, A y B.

${ }^{64}$ En el texto de al-Garnāṭî: عبدة القرشي.

${ }^{65}$ En el ms. de al-Dabbī hay un espacio en blanco de dos o tres palabras. F. Codera lo señala diciendo que falta el nombre de otra persona (D-C p. 259, n. 1). El copista deja un espacio en blanco porque posiblemente el original del texto que está trasladando tiene una laguna o una mancha precisamente en esta parte de la enumeración de los nombres, que impide su lectura.

${ }^{66}$ Se lee con dificultad بن ميسرة الفهمي, como así lo refleja D-A. Como aparecen una serie de nom-

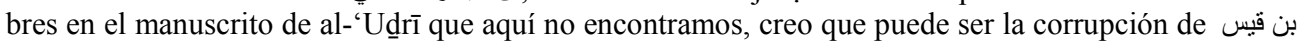
o habiéndose perdido palabras del nombre después de بن قيس التجيبي o el autor lo ha conectado con la palabra السهري

${ }^{67}$ En el texto de D-C قائم y en el texto de al-Garnâțī القهاس

${ }^{68}$ En H-LP no es mencionado ningún nombre de testigo. 
1. Tratado de capitulación que otorga por escrito 'Abd al-'Azīz Ibn Mūsà Ibn Nușayr para Tudmīr Ibn Gabdūšs, conocido

2. de cuyo nombre viene el nombre de Tudmīr pues él era su gobernante. Esta es copia del documento escrito: En el nombre de Allāh, el Clemente, el Misericordioso. Este es el documento escrito de 'Abd

3. al-'Azīz Ibn Mūsà para Tudmīr Ibn Gabdūs, en el que se ha de aplicar [lo referente] a la capitulación voluntaria: Se le concede el pacto instituido por Allāh, y su protección (عهد الله وذمته),

4. y la protección de su profeta (ذمة نبيه) -iAllāh le bendiga y le salve!--. Que [le garantizan que] no [se le] cambiará su status ni a él, ni a ninguno de sus compañeros [de gobierno] (أصحابه), ni se le cambiará o enajenará su dominio (ملكه). ${ }^{69}$ Que no

5. serán muertos, ni reducidos a esclavitud, ni serán separados de sus mujeres ni de sus hijos. No serán coaccionados en [lo referente a] su religión. No serán incendiadas

6. sus iglesias. No se le relevará de su dominio mientras sea leal amigo y cumpla nuestras condiciones impuestas. Que la capitulación abarca a siete

7. ciudades: Orihuela (Ūrīwāla), Balantala (B_1_ntala), Alicante (Laqant), Mula (Mūla), Buqasra (B_q_sra -o B_q_sruh-), Iyya (Iyya -o Iyyuh-) y Lorca (Lūrqa). Que no acoja

8. a ningún rebelde o enemigo, y no ataque a quienes tengan nuestro salvoconducto $(a m \bar{a} n)$. No nos ocultará ninguna noticia del enemigo que llegue a su conocimiento. Que él y sus compañeros [de gobierno] (أصحابه)

9. [que han entrado en el pacto] han de [entregar] cada año: un dinar, cuatro almudes de trigo, cuatro almudes de cebada, cuatro quistes de arrope (طِلاء), cuatro

10. quist de vinagre, dos quist de miel, dos quist de aceite. Y para todo esclavo la mitad de todo eso. Actuaron como testigos de este [documento y del acto jurídico]: 'Utimān Ibn Ab̄̄

11. 'Abda al-Qurašī, Habīib Ibn Abī 'Ubayda [......] Ibn Maysara al-Fahmī y Abū l-Qāsim al-Hudalāī. Se puso por escrito

12. en raŷab del año 94 de la Hégira (abril del 713 e.C.).

${ }^{69}$ Que pueden entenderse tanto como مِكس 'hacienda, propiedades', o como مُلكه 'soberanía'. 


\section{CONCLUSIONES DEL ANÁLISIS COMPARATIVO DE LOS TEXTOS DE LAS DOS VERSIONES BÁSICAS EN EL ÁMBITO DEL DERECHO}

Llama la atención que hay todo un vocabulario jurídico en los pactos conocidos que se repite de uno u otro modo. No hay más que acudir a la compilación de noticias y textos de tratados que hiciera Hamīd Allāh y comparar tanto el vocabulario, como los datos diversos de los tratados recogidos para extraer una serie de conclusiones de gran interés. ${ }^{70}$ Añadimos solo algunos ejemplos que se relacionan con los textos árabes del tratado de Tudmīr:

4.1. La expresión y orden ما نصحو mā naṣahū [exigimos] que nos informe, aparece también en el pacto con los cristianos de Naŷrān, en la época del profeta, año 10/631. ${ }^{71}$ En el texto de al-'Udrī aparece expresado como و لا يكتمنا خبرا علمه wa-lā yaktumu-nā jabaran 'alima-hu en el sentido de que no nos oculte ninguna información [sobre el enemigo] que tenga o llegue a su conocimiento, de lo que se puede deducir una mayor antigüedad en sus referentes léxicos en la versión original de este texto. En el de al-Dabbī aparece otra expresión ما تعبّّ ونصح mā ta'abbada wanașaha mientras sea leal amigo (esto es, mientras nos informe y no encubra noticia alguna sobre el enemigo), expresión que es diferente y más moderna.

4.2. En el documento dirigido a al-Mundīr Ibn Sāwà, aparece la condición de consultar o informar. ${ }^{12}$ En el pacto de Ŷuryān del año $18 \mathrm{H} \cdot .^{13}$ aparece la misma condición.

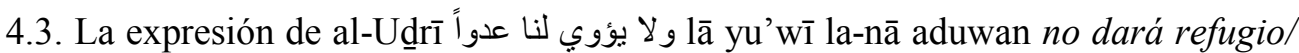
acogerá, a ningún rebelde o enemigo, aparece en el texto del pacto de Țabaristān, fecha del pacto $18 \mathrm{H} \cdot{ }^{74} \mathrm{En}$ el pacto de 'Umar con los cristianos de las ciudades y con los persas, aparece la misma condición: no acoger a los enemigos. ${ }^{75}$

4.4. En el pacto con el obispo de Ruha ${ }^{76}$ entre las obligaciones que se imponen a los vencidos, se exige un dinar y dos modios (escritos como en el texto de al-'Udrī ${ }^{77}$; el texto no tiene fecha pero es muy anterior al de al-Udrī.

4.5. La expresión و لا يكر هون على دينهم wa-lā yukrahuna 'alà dīni-him no se les forzará/coaccionará, en materia de su religión de la versión de al-'Udrī, aparece en el texto del pacto de Jerusalén. ${ }^{78}$

${ }^{70}$ ḤAMĪD ALLĀH AL-ḤAYDAR ĀBBĀDĪ, Muḥammad, Maŷmū' at al-wațā' 'iq al-siyāsīya fì l- 'ahd al-Nabawī wa-l-hilāfat al-Rāšida, El Cairo, 1941. $6^{\text {a }}$ ed. muy ampliada: Beirut, 1407 H./1987 e.C.

${ }^{71}$ HAMİD ALLĀH, op. cit., 81.

${ }^{72}$ Ibid., 57.

${ }^{73}$ Ibid., 250.

${ }^{74}$ Ibid., 251.

${ }^{75}$ Ibid., 100-3, pacto 102 .

${ }^{76} \mathrm{Ibid} ., 271$.

${ }^{77}$ Ver al respecto lo apuntado en la nota 26.

${ }^{78}$ Ibid., 268. 
4.6. En la mayoría de los pactos aparecen expresiones que hablan de pacto (ahd) y de la protección (dimma) عهذ الله وميثاقه وذمة أنبيائه ورسله 'ahd Allāh wa-mitâaqu-hu wa1-dimmat anbīyā'i-hi wa-rusuli-hi pacto instituido por Allāh y la protección de Su profeta y de Sus enviados. Tal como está la hallamos en el de Jerusalén y en el de

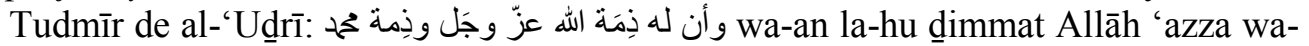
ŷalla wa-dimmat Muhammad tiene [el estatuto de] la protección de Allāh jensalzado y honrado sea!- y la protección de [el profeta] Muhammad. También en la versión de al-Dabbī: وأن له عهذ الله، [وذمته] وذمة نبيه wa-an la-hu 'ahd Allāh [wadimmatu-hu] wa-dimmat nabī-hi se le concede el pacto instituido por Allāh, y su protección y la protección de su profeta. Se ha de entender ذمة (dimma) protección en el sentido de lo estipulado legalmente en lo referente al estatuto jurídico de cristianos y judíos, según se indicaba en el Corán (dimmat Allāh), por un lado, y según los acuerdos firmados al respecto por el profeta (dimmat nabī-hi), en segundo lugar.

4.7. Es variable el número de los testigos que certifican la autenticidad y fidelidad de cada tratado: el pacto de Țabaristān tiene 5 testigos, ${ }^{79}$ el de Ŷurŷān tiene $4,{ }^{80}$ el de Jerusalén $4 .^{81}$ De esto se deduce que el que firmaran 8 testigos en el tratado de Tudmīr es más que notable, y realza su importancia, pues supone una garantía extraordinaria que se le concede a Teodomiro. Es tan inédito, que solo conservamos los 8 nombres originales en la versión de al-'Udīī, mientras que en la de al-Dabbī solo se enumeran 4 nombres (hay un espacio en mal estado y difícil lectra en el manuscrito en esta parte); por esto mismo, en la Bugya de al-Dabbī solo se alude a la participación en el pacto en las biografías de 3 de los 4 personajes citados en el documento que él transmite, y aunque en ella hallamos las biografías de otros de los 8 personajes que al'Ud́rī enumera, en estas biografías no se menciona que participaran.

Sería necesario hacer un estudio sistemático y comparado de estos aspectos de terminología jurídica, pero ello excedería al presente trabajo.

\section{LAS DOS LÍNEAS DE TRANSMISIÓN DEL TEXTO DEL TRATADO}

En nuestro estudio precedente sobre este tema ya expusimos que hay dos líneas de transmisión del texto en árabe del tratado de Tudmīr, o riwāyas: la de al-'Udirī y la de al-Ḍabbī, de quien proceden las versiones de al-Himyarī ${ }^{82}$ y al-Garnātī. ${ }^{83}$ Esto ya fue expuesto hace tiempo por otros investigadores y se ha dado por asumido; no

${ }^{79}$ Ibid., 251.

${ }^{80}$ Ibid., 250.

${ }^{81}$ Ibid., 268.

${ }^{82}$ El texto de al-Himyarī fue recogido en la ed. parc. ár. de HY-LP en el § تدمير pp. 62-63, mientras que en la más reciente ed. completa de Ḥ-A se encuentra en las pp. 131-132.

${ }^{83} \mathrm{El}$ texto árabe de al-Šarīf al-Ġarnātī está en G, t. II, p. 167. Es reproducido este mismo texto árabe, con la adición de una trad. esp. del mismo en CARMONA GONZÁLEZ, Alfonso, «Una cuarta versión de la Capitulación de Tudmir», en Sharq Al-Andalus. Estudios Árabes 9 (1992)16-17. 
obstante, presentamos aquí nuevas conclusiones al respecto basándonos en la información paleográfica y en el estudio del contenido de los textos. ${ }^{84}$

5.1.La primera conclusión de nuestro trabajo es que constatamos que el texto de al'Udri es de escasa calidad, presenta características arcaicas y contiene deficiencias gramaticales en árabe,

- Algunas de las cuales fueron arregladas por al-Ahwānī en su edición del texto (ver notas $9,11,17,34,36$ ).

- Otras las hemos puesto de relevancia tras el análisis del manuscrito.

- En la copia defectuosa del manuscrito que poseemos, hay unos borrones que hacen muy difícil la lectura de algunas partes (ver notas $8,15,17,18$, 21, 38).

- Es importante resaltar que en una primera redacción el texto se dejó en blanco el final de la línea sexta, así como toda la línea séptima. Con regularidad, a lo largo de la línea séptima están enunciados los topónimos de las siete ciudades del pacto. Esto evidencia que fueron escritos después de esta primera copia. Una posible razón para ello podría haber sido la dificultad para leer y entender bien los nombres de las ciudades en el documento fuente (n. 22).

El texto de al-'Uḍī se basó en otro más primitivo, más arcaico y con problemas en su estructura. Una explicación posible es que al-'Udnī tuviera la oportunidad de consultar el original del Tratado, o un traslado del mismo (esto es, una copia fiel que recogía lo que un copista creyó entender del documento original). Difícilmente pudo llegar el texto original al s. XI en que él escribe su obra. ${ }^{85}$

Por esto pensamos que es muy probable que Udrī pudo consultar, quizás en Murcia, quizás en Orihuela, un traslado en árabe que interpreta el documento original sin puntos diacríticos del tratado. Al-'Uḍrī intentó entender y trasladar esta

\footnotetext{
${ }^{84}$ Remitimos a los trabajos publicados por: MOLINA LÓPEZ, Emilio; PEZZI, Elena, «Últimas aportaciones al estudio de la Cora de Tudmīr (Murcia)», en Cuadernos de Historia del Islam 7 (19756)82-111. MOLINA LÓPEZ, Emilio, «El Kitāb Ihtișār iqtibās al-anwār de Ibn al-Huarrāṭ. El autor y la obra. Análisis de las noticias históricas, geográficas y biográficas sobre al-Andalus», en Quaderni di Studi Arabi. Atti del XIII Congresso dell'Union Européenne d'Arabisants et d'Islamisants (Venezia 29 settembre - 4 ottobre 1986) (1987-1988)540-560. CARMONA GONZÁLEZ, Alfonso, «Una cuarta versión de la Capitulación de Tudmir», en Sharq Al-Andalus. Estudios Árabes 9 (1992)11-17. POCKLINGTON, Robert, «El Pacto de Teodomiro y las siete ciudades.” Regnum Murciae. Génesis y configuración del reino de Murcia, Murcia, 2008, 72-84.

${ }^{85}$ Según L. Molina, esta obra tuvo dos redacciones: «entre el 459 y el 468 (1066-76) redacta su primera versión; en el 472 (1079-80) vuelve sobre el primitivo manuscrito y añade varias noticias históricas; finalmente entre ese año y el de su muerte $(478=1085)$ da la forma definitiva a su obra, que servirá de fuente a al-Qazwīn̄̄, al-Himyarī y al compilador del Dikr [biläd al-Andalus]», en MOLINA, Luis: «Las dos versiones de la Geografía de al-'Udīi», Al-Qanțara III (1982)260.
} 
copia imperfecta o deficiente a un lenguaje del s. XI, aunque lo consiguió a medias. Esta afirmación se fundamenta en varios motivos:

1. Estructura de algunas frases, que no se entienden bien. Algunos ejemplos:

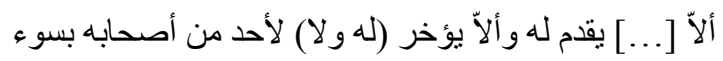

allā yuqaddama la-hu wa-allā yu'ajjar li-aḥadin min aṣhābi-hi bisū'

wa-lā yaftaraqu (fì-mā) bayna-hum

$$
\text { ولا يفترق (فيما) بينهم }
$$

wa-lā yunza'u 'an mulki-hi mā ta'abbada wa-naṣaḥa

2. La simple cata, antes enumerada, en el léxico jurídico comparado con los documentos de tratados más antiguos que nos han llegado nos induce a concluir que el texto de al-'Ud́dī posee un origen más antiguo. Por este motivo, y por el uso de los modios (en vez de los almudes que hace al-Dabbī, ver nota 26), pensamos que al'Udrī habría podido consultar el original del pacto, o un traslado fiel del mismo, también sin puntos diacríticos. Así se podría explicar tanto la tosquedad de su redacción, como el que dejara una línea y media para escribir más tarde unos topónimos que no había entendido bien en una primera lectura (sobre esto volvemos en $\S 7$ y 8 ).

También encontramos espacios en blanco en las líneas 2, 4, 5, 6, 13, posiblemente destinados a escribir alguna palabra con posterioridad a la primera escritura.

3. Al-'Ud̆rī es el único autor que cita el nombre del gobernante como Gandarīs.

En la otra línea de transmisión se menciona: al-Dabbī: Gabdūšš / Ḥ-A: Gandars y Ḥ-LP lo cita como Gabdūš / al-Garnātī: 'Abdūs.

4. En cuanto a los testigos que se citan:

- En la enumeración de los nombres de los testigos el segundo mencionado

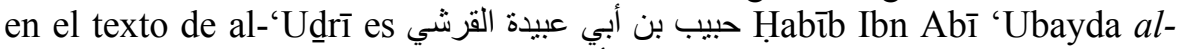

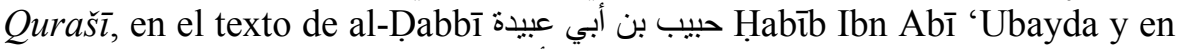
el texto de al-Garnāṭi Pero el verdadero nombre de este testigo es حبيب بن أبي عبدة الفهري Habīb Ibn Abī 'Abda al-Fihrī, quien era un compañero de 'Abd al-'Azīz Ibn Mūsà y uno de los rebeldes que le mataron. ${ }^{87} \mathrm{Y}$ en Al-Nuŷūm al-zāhira se dice que

\footnotetext{
${ }^{86}$ En el manuscrito de Al-Dabbī hay un punto arriba y otro abajo, lo que permite leerlo de dos formas posibles: Gabdūš o Gandūš.

${ }^{87}$ Véase Kitāb al-mu 'ŷib fì taljīs ajbār al-Magrib, ed. ár. DOZY, Reinhardt P., The History of Almohades preceded by a sketch of the History of Spain, from the time of the conquest till the Reign of Yüsof Ibn-Téshüfin and of the History of the Almoravides by Abdo-'l-Wáhid al-Marrékoshi. Edited from a Manuscript in the University Library of Leiden. Second Edition, Revised and corrected, Amsterdam, 1968, v. I, p. 3.
} 
es quien mató a 'Abd al-'Azīz Ibn Mūsà y su nombre es Habīb Ibn Abī 'Ubayd Ibn 'Uqba Ibn Nāfi' al-Fihrī, y en el Tārīj al-umam de al-Ṭabarī, se afirma que trajo la cabeza de 'Abd al-'Azīz Ibn Mūsà al califa omeya Sulaymān Ibn 'Abd al-Malik. ${ }^{88}$ Este equívoco se justificaría si al-'Ud̆rī al consultar el original, o un traslado fiel, debido a su caligrafía hubiera encontrado problemas para entender adecuadamente algunos nombres, y él $-\mathrm{O}$ quien hubiera hecho el traslado que consultó- hubieran restituido القرشي alQurašī en vez de الفهري al-Fihrī.

- El que al-'Uḍrī escriba el segundo testigo como al-Qurašĩ cuando debería ser al-Fihrī, y el octavo y último interprete 'Āṣim donde debería ser Qāsim, nos hacen pensar si estos equívocos en los nombres se entenderían por la ausencia de puntos de las letras árabes originales. O por el deterioro del original en esta parte final del documento.

- En el manuscrito de al-Ḍabbī, tras un espacio en blanco aparece el nombre de Ibn Maysara al-Fahmī, y el último nombre D-C lo escribe Abū Qā'im alHudalī. Pero en el texto del manuscrito escurialense se puede leer Abū alQāsim al-Hudalīi, igual que el nombre mencionado por al-'Uḍrī.

- El manuscrito de al-'Udrī enumera los nombres de 8 testigos. El de alDabbī cita 3 nombres de testigos y un cuarto es un nombre deformado de los otros 3 que cita al-'Udrī. Se explica por la existencia de un espacio en blanco, que indicaría que no se ha entendido o no está claro (quizás por deterioro) esta parte del texto que se copia. Así se explica la corrupción del nombre citado en la nota 66 .

5. En la Tarșī ‘ al-ajbār de al-'Uḍrī aparece una expresión que no encontramos en ninguno de los textos de la otra riwāya: وما بعث به أنبياءه ورسئَّه 'wa-mā ba'ata bi-hi anbiyā' wa-rusuli-hi según lo que ha enviado [por mediación de] sus profetas y sus mensajeros.

6. En la obra de al-'Ud́rī no aparecen detalles que encontramos en la otra línea textual, es un texto con menos detalles que los otros:

- En al-'Ud̆ī no aparecen tres detalles importantes del pago de la ŷizya que encontramos en la línea textual dependiente de al-Ḍabbī:

- que incluye وأربعة أقساط طلاء wa-arba‘a aqsāṭ ṭalā', cuatro quistes de arrope.

- pone solo قسط زيت qisṭ zayt un quiste de aceite; al-Ḍabbī y al-Garnâț̣i escriben وقسطى زيت qistà zayt, dos quistes de aceite.

${ }^{88}$ Habīi Ibn Abī 'Ubayd al-Fihrī, según Ibn Tağrībirdī Al-Nuŷūm al-zāhira, edición de Dār alKutub al-'Ilmīya, vol. IV, p. 44. Al-Dahabī en su Tārīj al-Islām (ed. ár MA`RŪF, Beirut, 1991, v.VI, p. 267) y al-Ḥumaydī en su Ŷadwat al-Muqtabis lo nombran Ḥabīb Ibn Abī Ubayda al-Fihrī. 
- encontramos una importante diferencia: Al-“Udrīi: وأربعة [أمداء] من قمح و أربعة cuatro modios de trigo, cuatro modios de cebada mientras que al-Dabbī: وأربعة أمداد قمح، وأربعة أمداد شعير cuatro almudes de trigo, cuatro almudes de cebada. En la nota 26 ya hemos precisado esta diferencia, que consideramos de gran importancia. Esta mención entendemos que hace más tardía la versión del texto de al-Ḍabbī مُ جد ج جداد "almud", la citada por al-Dabbī, es medida de capacidad de los sólidos que aparece corrientemente en libros de fiqh más tardíos), en contraposición al término más antiguo usado por al-“Udrī: مُدْيُ ج أمْدَاء "modio". En otros pactos antiguos previos,

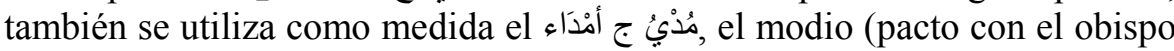
de Ruhā), ${ }^{89}$ lo cual abunda en la antigüedad y verosimilitud de su versión. Esta metátesis y actualización ortográfica, nos induce a plantear que alDabbī recibió su texto por dictado y que no lo leyó (o que copió un texto cuyo autor lo había recibido por audición, no leído en un traslado escrito).

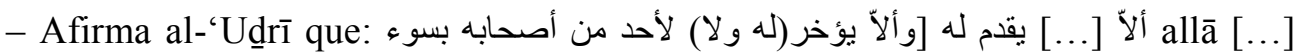
yuqaddama la-hu wa-allā yu'ajjar (la-hu wa-la) li-aḥadin min aṣhābi-hi bisū' [Se le garantiza] que no [...] se le hará daño ni a él ni a sus compañeros, sin diferencia alguna

- Mientras que en al-Ḍabbī y al-Garnāț̄e expresan otro significado: ألا يقدم لها allā yuqaddama la-hu, wa-lā liaḥadin min aṣḥābi-hī, wa-lā yu'ajjar wa-lā yunza'u 'an mulki-hi, Que [le garantizan que] no [se le] cambiará su status ni a él, ni a ninguno de sus compañeros [de gobierno], ni se le cambiará o enajenará su dominio (ملكه).

- En al-'Uḍī no aparecen otras condiciones que sí recoge al-Ḍabbī en las líneas 7-8:

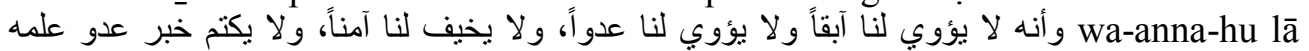
yu'wī la-nā ābiqan wa-lā yu'wī la-nā 'aduwan wa-lā yujīifu la-na āminan wa-lā yaktum jabar 'aduw 'alima-hu que no acoja ningún enemigo o rebelde y no ataque a quienes tengan nuestro salvoconducto (amán)

7. Respecto a las ciudades que aparecen: Al-'Uḍī dejó para el final la correcta escritura de los topónimos, puesto que al estar escritos sin puntos diacríticos, no le serían comprensibles varios de ellos. Se deja en blanco para su inclusión posterior parte de la línea $6^{\mathrm{a}}$ y la $7^{\mathrm{a}}$ entera. Luego, escribe en ese espacio primero los topónimos de identificación segura, y deja para el final los que tiene menos claros, e incluso añade Ilš como interpretación de un Buqașra que parece que no supo leer o interpretar.

8. El que la enunciación al-'Udnrī cambie Buqasra (B_q_sra/uh بقره) por Ilš (إلثره) Elche) nos lleva a pensar que:

${ }^{89}$ HAMĪD ALLĀH, op. cit., 271. 
A. O la deja en último lugar de su enumeración, luego es la que más dudó a la hora de interpretar. Se decidió al final por esta lectura del topónimo dudoso como Ilš, que la otra cadena de transmisión recoge como Buqașra. Evidentemente no entendió el Buqașra, y conjeturó que una ciudad importante debió ser Ilš. Pero no hay posibilidad ninguna de que dudara en la lectura de un nombre escrito, dada la gran diferencia entre ambos.

B. O interpretó adecuadamente este topónimo, a la luz del manuscrito original $-\mathrm{o}$ de un traslado casi idéntico-, casi con seguridad sin puntos diacríticos. En este original estarían enunciados los topónimos en un orden diferente a la transmisión de al-Ḍabbī (y a la de al-Rāzī).

9. Ambas transmisiones textuales están interrelacionadas, puesto que tienen una estructura bastante parecida. Son además textos complementarios, aunque diferentes. No encontramos que pueda haber un texto base fuente común de las dos líneas de transmisión, por haber muchas diferencias entre ambas.

La coincidencia en el error de nombrar al segundo de los testigos con la nisba al-Qurašī en vez de al-Fihrī quizás pueda interpretarse como un origen común a las dos riwāyas, pero tampoco es un argumento demostrativo categórico.

\subsection{Respecto a la segunda riwāya textual:}

1. Se puede fijar una línea textual única entre al-Ḍabbī, al-Ḥimyarī y al-Garnāṭ̂. Aunque hallemos algunos ligeros cambios entre ellos, puede verse que estamos ante un texto con estructura y contenido muy similar.

2. Hallamos alguna ligera diferencia entre ellos que puede cambiar el significado completamente. Como por ejemplo:

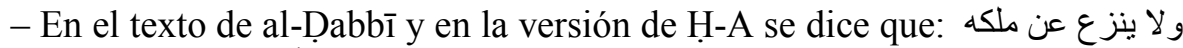

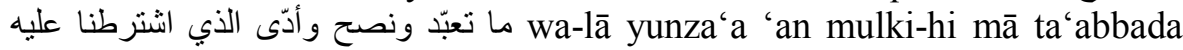
wa-nașaha wa-addà allad̄i ištaraṭnā 'alay-hi No se le relevará de su dominio mientras sea leal amigo, y cumpla nuestras condiciones impuestas.

- En el texto que plantea H-LP, después de no quemar sus iglesias, se añade otra condición, que tiene más sentido que la frase anterior: ولا ينزع عن كنائسة ما يُعبد وذلك ما أدَّى الذي انشترطنا عليه wa-d̄ālika mā addà allad̄i ištarațnā 'alay-hi No se quitará lo que adoran en sus iglesias mientras nos informe y cumpla nuestras condiciones impuestas.

- En el texto de al-Garnātị hay una laguna, y aparece un texto similar, pero aún más correcto ولا بنزع عن ملكه ما تعبّّ ونصح wa-lā yunza'a 'an mulki-hi mā ta'abbada wa-nașaha No se quitará su dominio mientras nos informe y aconseje

3. Estos textos están en general bien redactados y especifican con más detalle las condiciones generales del tratado. Esto parece indicar que la base del mismo no fue 
el imperfecto texto escrito que usara al-'Uḍrī sino, más bien, una fuente oral que le refiere de memoria el pacto. Esto se explica por:

- La mayor unidad del texto en sí mismo.

- Se refieren los detalles en cuanto a las condiciones, pero no así en cuanto a los nombres de los testigos del tratado.

4. Ello refleja que estos textos han copiado uno del otro, de modo que un probable stemma sería el siguiente: Al-Rušățī > al-Ḍabbī y posteriormente Al-Ḍabbī > alḤimyarī y al-Ḍabbī > al-Garnāțī.

5. La enunciación de los topónimos de las ciudades en estos tres textos es muy similar. La diferencia en la enumeración viene determinada en al-Garnāțī, debido a su ausencia de mención de Laqant e Iyya. El cambio de orden respecto a al-'Uḍrī está en que éste cita a Lorca en tercer lugar mientras que los otros la citan al final.

\subsection{Propuesta de stemma}

Ya se ha avanzado una propuesta de stemma de las tres transmisiones principales que conocemos del texto y los detalles del tratado de Tudmīr en otro estudio; ${ }^{90}$ al final del mismo se adjunta un gráfico explicativo de la hipótesis interpretativa, recogiéndose las diversas posibilidades e interrogantes en la transmisión de los textos del tratado que a fecha de hoy se mantienen.

En el trabajo presente se ha ampliado aquél análisis comparativo de los dos textos principales. El tema dista de estar cerrado, pero la actualización de los planteamientos sobre estas dos líneas de transmisión textual del tratado supone un nuevo paso adelante para el conocimiento del texto y de las circunstancias de su difusión y transmisión.

\section{FUENTES ÁRABES CITADAS ABREVIADAMENTE}

D-C = Al-Dabbī. Michaelis CASIRI (Al-Gaziri) ed. parcial ár., trad. lat. Bibliotheca Arabico-Hispana Escurialensis sive librorum omniun mss. quos Arabiche ab auctoribus magnam partem Arabo-Hispanis compositos, Bibliotheca Coenobii Escurialensis complectitur, recensio et explanatio. Madrid: 1760-1770, 2 vols. (976 pp.). Reimpresión: Madrid, 1970.

D-CR = Al-Ḍabbī. Francisco CODERA \& Julián RIBERA ed. Bibliotheca ArabicoHispana. Tomus III. Desiderium Quaerentis Historiam Virorum populi Andalusiae (Dictionarium biographicum) ab Adh-Dhabbi scriptum: ad fidem codicis Escurialensis arabice nunc primum ediderunt, indicibus additis Franciscus Codera in Universitate Matritensi Arabicae linguae professor ordinarius et Regiae Historicae Academiae Sodalis et Julianus Ribera. Madrid: Imp. José de Rojas, 1885.

${ }^{90}$ FRANCO-SÁNCHEZ, F., op. cit, p. 343. 
DQ-A = Al-Ḍabbī. Ibrāhīm al-Abyārī ed. ár. Bugyat al multamis fì ta'rīh rîyāl ahl al-Andalus li-l-Dabbī. 599 H. / 1203 M. El Cairo-Beirut: Dār al-Kitāb al-Mișrī / Dār al-Kitāb al-Lubnān̄̄ (Col. Al-Maktabat al-Andalusīya, 14-15), 1410 H. / 1989 e.C. 2 vols.

G = Al-Šarīf al-Garnāțī, Abū-l-Qāsim Muḥammad. Kitāb Raf' al-ḥuŷub al-masțūra ft mahāsin al-Maqșūra. [El Cairo]: Maṭba'a al-Sa'āda bi-Ŷiwār Muhāazaẓa Miṣr, 1244 H./1828 e.C.

H-LP: Al-Himyarī. Évariste Lévi-Provençal ed. parc. ár., trad. fr. La Péninsule Ibérique au Moyen Âge d'après le "Kitāb ar-rawd al-mi țār fi habar al-akțâr" d'Ibn 'Abd al-Mun 'im al-Himyarī. Leiden: E. J. Brill, 1938.

Ḥ-A: Al-Ḥimyarī, ed. ár. completa: Iṇsān 'Abbās: Al-Rawd al-mi țār fì habar alaqtār. Mu 'ŷam ŷugrāfì. Ta'līf Muhammad Ibn 'Abd al-Mun 'im al-Himyarī. Beirut: Librairie du Liban, 1975.

Hu-C: Al-Humaydī. Ŷadwat al-muqtabis fì dikr wulāt al-Andalus, tā'līf al-

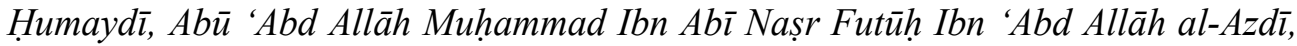
al-mutawaffi sanat 488 hiŷrì. El Cairo: Dār al-Mișrīya li-1-Ta'līf wa-1-Tarŷama (Col. al-Maktaba al-Andalusīya, 3), 1966.

IK: Ibn Kat̄īr al-Dimašqī. 'Alī Šīrī ed. crít, ár. Al-Bidāya wa-l-nihāya. El Cairo: Dār al-Iḥyā' Turāt al-'Arabī, 1988. 14 vols.

IT: Ibn Tağrībirdī. Al-Nuŷūm al-zāhira fì mulūk Miṣr wa-l-Qāhira. El Cairo: Dār alKutub al-Mișrīya, 1929-1949. 10 vols.

R: Al-Rušāṭī. Emilio Molina López \& Jacinto Bosch Vilá ed. ár. Kitāb Iqtibās al-

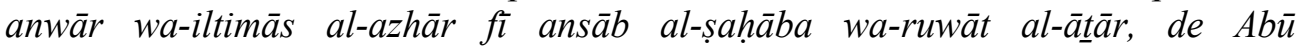
Muhammad al-Rušăț̄i (m. 542-1147). Ibn al-Jarrāt al-Išbūì̄ (m. 581/1186). AlAndalus en el Kitāb Iqtibās al-anwār y en el Ijtișār Iqtibās al-anwār. Madrid: C.S.I.C. / I.C.M.A., 1990.

Ț: Aț-Ṭabarī. Ta'rīj al-umam wa-l-mulūk. Beirut: Dār al-Kutub al-'Ilmīya, 1407 H. 5 vols.

U-A: Al-'Uḍrī. 'Abd al-'Azīz al-Ahwān̄̄ ed. parc. ár. Ahmad Ibn 'Umar Ibn Anas al'Ud̆rī. Nușūș 'an al-Andalus. Fragmentos geográfico-históricos de Al-Masālik ilà $\hat{y} a m \bar{\imath} ` a l$-Mamālik. Madrid: Instituto Egipcio de Estudios Islámicos en Madrid, 1965. 